ENDF/B-5 FISSION PRODUCT

CROSS SECTION EVALUATIONS

R. E. Schenter

T. R. England

December 1979

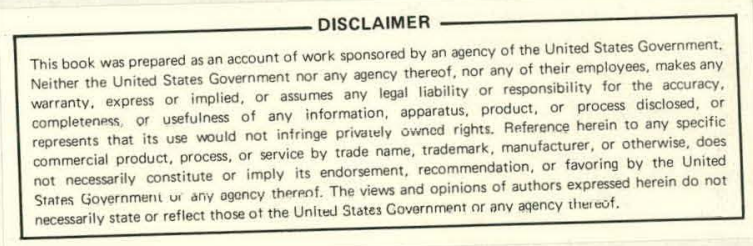

NEANDC Specialist Meeting on Neutron Cross

Sections of Fission Product Nuclei

Bologna, Italy

December 12-14, 1979

HANFORD ENGINEERING DEVELOPMENT LABORATORY

Operated by Westinghouse Hanford Company, a subsidiary of

Westinghouse Electric Corporation, under the Department of

Energy Contract No. I DE-AC14-76FF02170

COPYRIGHT LICENSE NOTICE

By acceptance of this article, the Publisher and/or recipient acknowledges the U.S

Government's right to retain a nonexclusive, royalty free license in and to any cnpyright covering this paper. 


\section{DISCLAIMER}

This report was prepared as an account of work sponsored by an agency of the United States Government. Neither the United States Government nor any agency Thereof, nor any of their employees, makes any warranty, express or implied, or assumes any legal liability or responsibility for the accuracy, completeness, or usefulness of any information, apparatus, product, or process disclosed, or represents that its use would not infringe privately owned rights. Reference herein to any specific commercial product, process, or service by trade name, trademark, manufacturer, or otherwise does not necessarily constitute or imply its endorsement, recommendation, or favoring by the United States Government or any agency thereof. The views and opinions of authors expressed herein do not necessarily state or reflect those of the United States Government or any agency thereof. 


\section{DISCLAIMER}

Portions of this document may be illegible in electronic image products. Images are produced from the best available original document. 


\title{
ENDF/B-5 FISSION PRODUCT CROSS SECTION EVALUATIONS*
}

\author{
R. E. Schenter \\ Hanford Engineering Development Laboratory \\ P.0.Box 1970 \\ Richland, Washington 99352 \\ T. R. England \\ Los Alamos Scientific Laboratory \\ P.0.Box 1663 \\ Los Alamos, New Mexico 87545
}

\begin{abstract}
Cross section evaluations have been made for the 196 fission product nuclides on the ENDF/B-5 data files. Most of the evaluations involve updating the capture cross sections of the important absorbers for fast and thermal reactor systems. This included updating thermal values, resonance integrals, resonance parameter sets and fast capture cross sections. For the fast capture results generalized least-squares calculations were made-using the-computer code FERRET. Input for these cross section adjustments included nuclear models calculations and both integral and differential experimental data results. The differential cross sections and their uncertainties were obtainef from the CSIRS library. Integral measurement. results came from CFRMF and STEK Assemblies 500, 1000, 2000, 3000, 4000. Comparisons of these evaluations with recent capture measurements will be presented.
\end{abstract}

\section{Introduction}

The ENDF/B-5 fission product file consists of 877 nuclide- evaluations. Of these, 196 have full cross section data sets which contain:values for total, elastic, inelastic, capture and angular distributions for the. energy range $10^{-5} \mathrm{ev}$ to $20 \mathrm{MeV}$. Table I lists the 196 nuclides. The file is basically an update of ENDF/B-4, where most of the changes occur for the fast and thermal capture cross sections. These changes involve the use of important new evaluation techniques and recent experimental results from both integral and differential measurements.

In this paper we present typical results illustrating these new: techniques where use was made of a generalized least-squares adjustment procedure/l/ to obtain a nominal cross section curve and uncertainty information

*Work supported by DOE contract DE-AC14-FF02170. 
Table I. Fission Product Nuclides with Cross Section Data for ENDF/B-5.

1. 32 Ge 72

2. $32 \mathrm{Ge} 73$

3. $32 \mathrm{Ge} 74$

4. 32 Ge 76

5. 33 As 75

6. $34 \mathrm{Se} 75$

7. $34 \mathrm{Se} 76$

8. 34 Se 77

9. 34: Se 78

10. 34 Se 80

11. 34 Se 82

12. $35 \mathrm{Br} 79$

13. $35 \mathrm{Br} 81$

14. $36 \mathrm{Kr} \quad 78$

15. $36 \mathrm{Kr} \quad 80$

16. $36 \mathrm{Kr} \quad 82$

17. $36 \mathrm{Kr} \quad 83$

18. $36 \mathrm{Kr} \quad 84$

19. $36 \mathrm{Kr} \quad 85$

20. $36 \mathrm{Kr} \quad 86$

21. $37 \mathrm{Rb} 85$

22. $37 \mathrm{Rb} \quad 86$

23. $37 \mathrm{Rb} \quad 87$

24. $38 \mathrm{Sr} 84$

25. $38 \mathrm{Sr} 86$

26. $38 \mathrm{Sr} 87$

27. $38 \mathrm{Sr} 88$

28. $38 \mathrm{Sr} \quad 89$

29. $38 \mathrm{Sr} 90$

30. 39 Y 89

31. $39 . Y$

32. $39 \mathrm{Y}$

33. $40 \mathrm{Zr}$

34. $40 \mathrm{Zr} \cdot 91$

35. $40 \mathrm{Zr} \quad 92$

36. $40 \mathrm{Zr} 93$

37. $40 \mathrm{Zr} 94$

38. $40 \mathrm{Zr} \quad 95$

39. $40 \mathrm{Zr} .96$

40. $41 \mathrm{Nb} 93$

$41.41 \mathrm{Nb} 94$

42. $41 \mathrm{Nb} 95$

43. 42 Mo 92

44. 42 Mo 94

45. 42 Mo 95

46. 42 Mo 96

47. 42 Mo 97

48. 42 Mo 98

49. 42 Mo 99

50. 42 Mo 100
51. 43 TC 99

52. $44 \mathrm{Ru} 96$

53. 44. Ru 98

54. $44 \mathrm{Ru} 99$

55. $44 \mathrm{Ru} 100$

56. $44 \mathrm{Ru} 101$

57. $44 \mathrm{Ru} 102$

58. $44 \mathrm{Ru} 103$

59. 44 Ru 104

60. $44 \mathrm{Ru} 105$

61. $44 \mathrm{Ru} 106$

62. $45 \mathrm{Rh} 103$

63. $45 \mathrm{Rh} 105$

64. $46 \mathrm{Pd} 102$

65. 46 Pd 104

66. $46 \mathrm{Pd} 105$

67. $46 \mathrm{Pd} 106$

68. $46 \mathrm{Pd} 107$

69. $46 \mathrm{Pd} 108$

70. $46 \mathrm{Pd} 110$

71. $47 \mathrm{Ag} 107$

72. $47 \mathrm{Ag} 109$

73. $47 \mathrm{Ag} 111$

74. 48 Cd 106

75. $48 \mathrm{Cd} 108$

76. $48 \mathrm{Cd} 110$

77. $48 \mathrm{Cd} 111$

78. 48 cd 112

79. 48 Cd 113

80. 48 Cd 114

81. $48 \mathrm{Cd} 115 \mathrm{M}$

82. 48 Cd 116

83. 49 In 113

84. 49 In 115

85. $50 \mathrm{Sn} 112$

86. 50 Sn 114

87. 50 Sn 115

88. 50 Sn 116

89. 50 Sn 117

90. 50 Sn 118

91. 50. Sn 119

92. $50 \mathrm{Sn} \cdot 120$

93. 50 Sn 122

94. 50 Sn 123

95. 50 Sn 124

96. 50 Sn 125

97. 50 Sn- 126

98. 51 Sb 121

99. 51 Sb 123

100. 51 Sb 124
101. 51 Sb 125

102. $51 \mathrm{Sb} 126$

103. 52 Te 120

104. 52 Te 122

105. 52 Te 123

106. 52 Te 124

107. 52 Te 125

108. 52 Te 126

109. $52 \mathrm{Te} 127 \mathrm{M}$

110. 52 Te 128

111. 52 Te 129M

112. 52 Te 130

113. 52 Te 132

114. 53 I 127

115. 53 I 129

116. 53 I 130

117. 53 I 131

118. 53 I 135

119. 54 Xe 124

120. 54 Xe 126

121. 54 Xe 128

122. 54 Xe 129

123. 54 Xe 130

124. 54 Xe 131

125. 54 Xe 132

126. 54 Xe 133

127. 54 Xe 134

128. 54 Xe 135

129. 54 Xe 136

130. - 55 Cs 133

131. 55 Cs 134

132. 55 Cs 135

133. 55 Cs 136

134. 55 Cs 137

135. 56 Ba: 134

136. $56 \cdot \mathrm{Ba} 135$

137. 56. Ba 136

138. $56 \mathrm{Ba}-137$

139. 56 . Ba 138

140. 56 Ba 140

141. 57. La 139

142. 57 La 140

143. 58 Ce 140

144. 58 Ce 141

145. 58 Ce 142

146. 58 Ce 143

147. 58 Ce 144

148. 59. $\mathrm{Pr} 141$

149. 59 Pr 142

150. 50 Pr 143
151. $60 \mathrm{Nd} 142$

152. $60 \mathrm{Nd} 143$

153. $60 \mathrm{Nd} 144$

154. $60 \mathrm{Nd} 145$

155. $60 \mathrm{Nd} 146$

156. $60 \mathrm{Nd} 147$

157. 60. Nd 148

158. $60 \mathrm{Nd} 150$

159. $61 \mathrm{Pm} 147$

160. $61 \mathrm{Pm} 148$

161. $61 \mathrm{Pm} 148 \mathrm{M}$

162. $61 \mathrm{Pm} 149$

163. $61 \mathrm{Pm} 151$

164. 62 Sm 144

165. 62 Sm 147

166. 62 Sm 148

167. 62 Sm 149

168. $62 \mathrm{Sm} 150$

169. 62 Sm 151

170. 62 Sm 152

171. $62 \mathrm{Sm} 153$

172. $62 \mathrm{Sm} 154$

173. 63 Eu 151

174. $63 \mathrm{Eu} 152$

175. 63 Eu 153

176. 63 Eu 154

177. 63 Eu 155

178. $63 \mathrm{Eu} 156$

179. $63 \mathrm{Eu} 157$

180. 64 Gd 152

181: 64 Gd 154

182. 64 Gd 155

183. 64 Gd 156

184. 64 Gd 157

185. 64 Gd 158

186. 64 Gd 160

187. .65 Tb 159

188. 65 Tb 160

189. -66. Dy 160

190. 66 Dy 161

191. 66 Dy 162

192. - 66 Dy 163

193. -66 Dy 164

194. -67 Ho 165

195. $68 \mathrm{Er} 166$

196. $68 \mathrm{Er} 167$ 
in the -form of a covariance matrix which linked energy points. - This procedure involves calculations which use the finite element representation of the FERRET / 2 / data adjustment code. Also presented in this paper will be a study of thermal reactor absorption sensitivity to capture cross section changes in important fission products.

\section{FAST CAPTURE}

Table II lists the 25 most important fission product absorbers in a fast reactor core with their percent contribution to total absorption. Emphasis for ENDF/B-5 has been on updating the capture cross sections of these top -: absorbers plus an additional 50 more. Typical results of these evaluations are shown in Figures 1-14, where the "Adjusted" curves will be used for ENDF/B-5. Also shown is the data used as input to the FERRET code. This includes both differential and integral data and their uncertainties. Also inputted to the calculation was an "a priori" description which combined multi-group average cross sections obtained from resonance parameters for the resolved resonance region with "smooth" average cross section from ENDF/B-4 for the higher energy region. The resonance parameters used were from ENDF/B-4 or BNL-325/3/ as indicated. The histogram or muiti-group cross section description in the resonance region is required for the FERRET leastsquares calculation because following the exact resonance structure takes too many points for the standard computer calculations, especially for the covariance matrix part.

The integral data came from reaction rate measurements in STEK Assemblies $500,1000,2000,3000,4000 / 4 /$ and CFRMF $/ 5 /$. ENDF/B-4 evaluations also used earlier CFRMF measurements which helped normalize nuclear models calculations made with the Hauser-Feshbach computer code NCAP /6/.

This type of approach which quantitatively combines three evaluation sources, diverges somewhat from the usual. ENDF/B philosophy which is to rely. essentially on differential results with some adjustment due to integral results. This method also differs from the Japanese and European procedures in which either only differential or only integral values are exclusively used. For individual fission products, however, it is felt that this approach has substantial promise since many of the problems associated with the use of integral data are greatly simplified in dealing with a single nuclide. As can be seen in Table II, for most of the nuclides which have experimental measurements, the differential data is discrepant. Consequently, it is hoped that use of the integral results will supplement our information and help resolve these discrepancies. Another advantage of the procedure is that it provides quantitative uncertainty information in the form of covariance matrices which can be easily translated into ENDF/B formats. Obviously there-are problems associated with using integral data such as self shielding effects, mixtures of isotopes -for the same element, flux and adjoint flux determinations and uncertainty assignments and these will have to be examined carefully to have a viable method.

Figure 1 shows results for the important absorber $\mathrm{Sm149}$. As can be seen from the curves, significant changes occur in going -from ENDF/B-4 to ENDF/B-5. The ENDF/B-4 result was made with nuclear model calculations where no previous experimental data existed in 1973. Also shown in Figure 1 are "Adjusted" cross sections using the FERRET code, comparing various results when only integral data is used or differential data is used. For the Sml49 case, the results are consistent with each other. For some of the other cases shown in Figures 5-14 this does not necessarily occur. 
Table II. Twenty five most "important" fission product absorbers in-fast reactor cores. Also shown are fast integral and differential experiments. which have published results as of November $=1979$. The CFRMF, STEK and differential data were used in the HEDL-PETTEN evaluations for ENDF/B-5.

Percent Contribution. Nuclide.

1. $\mathrm{Pd} 105$

2. TC 99

3. $\mathrm{Ru} 101$

4. Pd 107

5. Rh 103

6. Cs 133

7. $\mathrm{Pm} 147$

8. Sm 149

9. Nd 145

10. Ru 102

11. Cs 135

12. Mo 97

13. Ag 109

14. $\mathrm{Ru} 106$

1.5. Nd 143

16. Xe 131

17. Sm 151

18. Mo 95 .

19. Ru 104.

20. Eu 153

21. : Mo 98

22. Ce 144

23. I 129

24. Mo 100

25. $\operatorname{Pr} 141$
9.9

8.6

7.7

6.2

5.5

4.9

3.5

3.4

3.4

3.3

3.0

2.9

2.7

2.3

2.3

1.9

1.9

1.5

1.3

T. 3

1.2

1.1

1.0

0.9

$\frac{0.9}{82.6}$
EBR-2 CFRMF STEK tial Data* Data:

\section{Differen- Diff: \\ iscrepant}

$M, S$,

$S, \ldots$

$\mathrm{M}, \mathrm{S}$

no data

$M, S, \cdots$

..

$-$

no data

one data set

one data set

$M, S, \ldots$

no data

$-$

Mu,..

..

$-$

Mu

-

$-$

Mu,...

$M, S$

Mu,...

$-$

no data

no data

Mu,...

...

no data

one data set

no data

no data

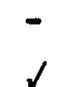

$\checkmark$

$$
-
$$

$\checkmark$ 
Error estimates are outputted from the FERRET code and Figure 2 shows fractional uncertainty versus energy for the Sm149 case, where the final uncertainty changes from about $60 \%$ to $10 \%$ (10) in going from ENDF/B-4: to ENDF/B-5. Figures 3 and 4 show the cases of adjusted curves using STEK : measurements compared to recent integral results at. EBR-EI adjusted by Ander 1 et al.., $/ 7 /$ for $S m 149$ and $5 m 147$. The full energy region (1 ev - $10 \mathrm{MeV}$ ) evaluation is shown in Figure 5 for Mo97. Comparisons to recent differential measurements by Macklin, et a1., /8\% is shown in Figures -6-10-for Ru101,: Ru102, Rul104; PdT04, and Pd108. Finally, results for four of the top twentyfive fission product absorbers (TC99, Rh103, Ag109 and Cs133) are given in Figures 11-14. 


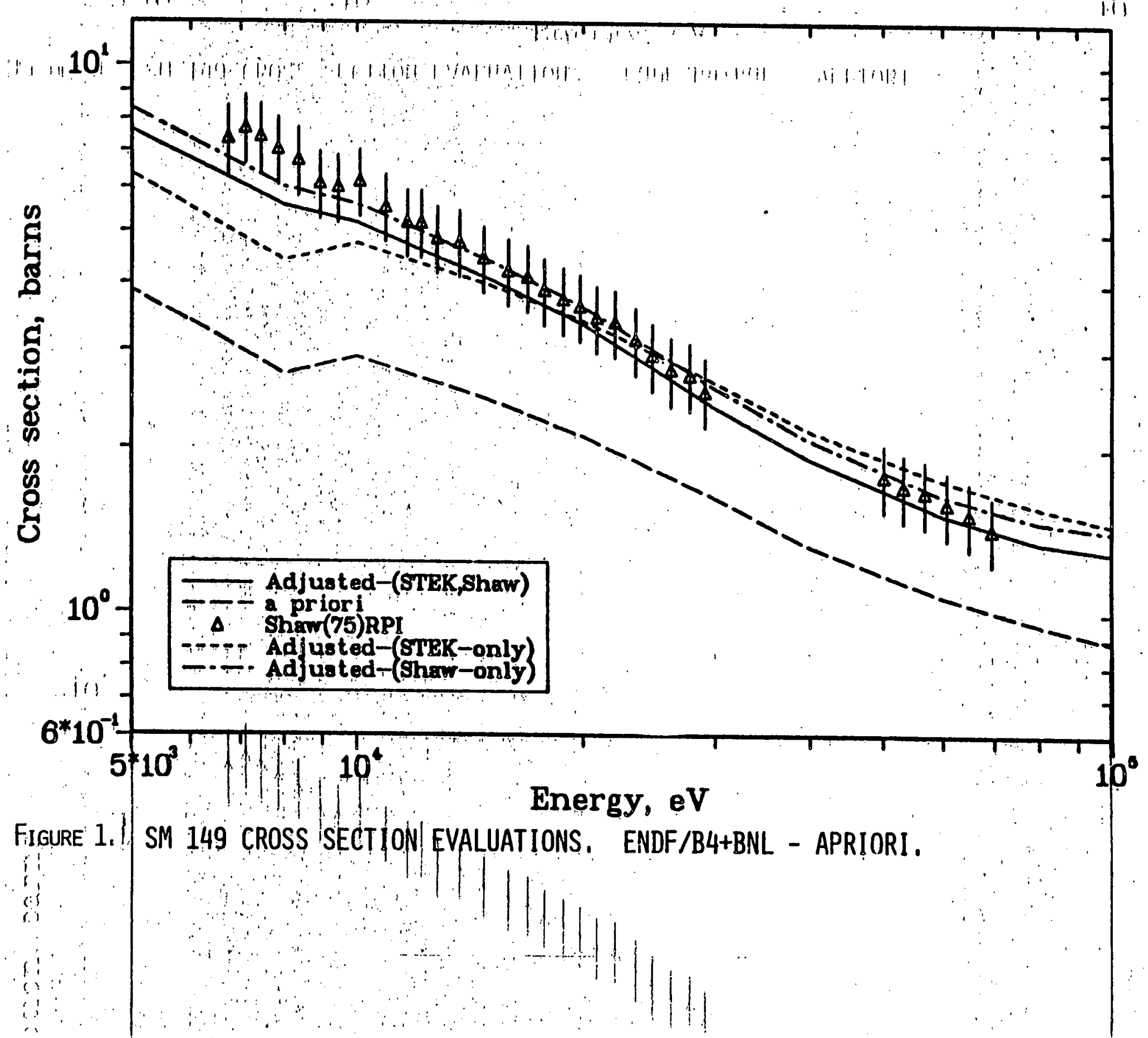




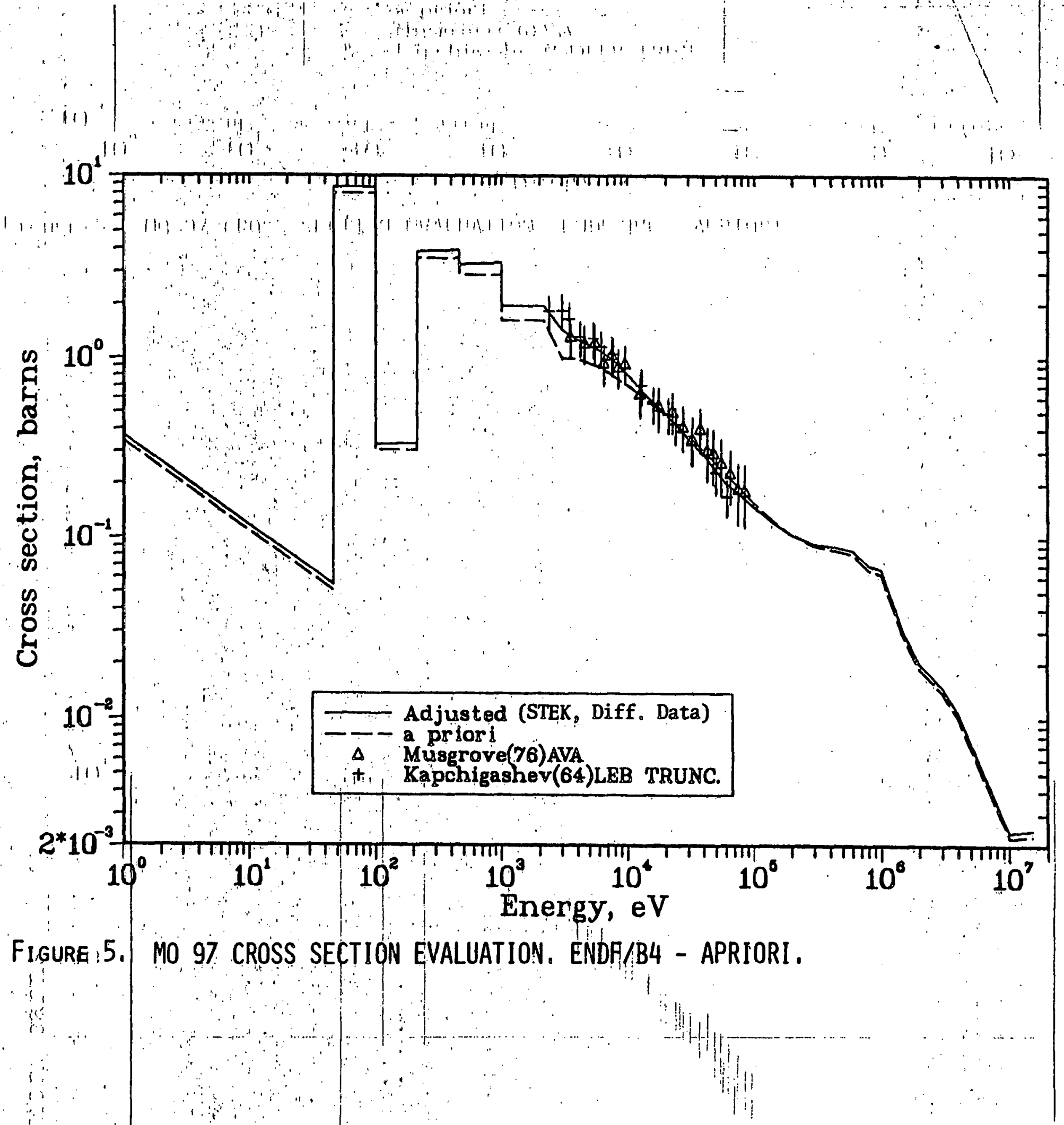




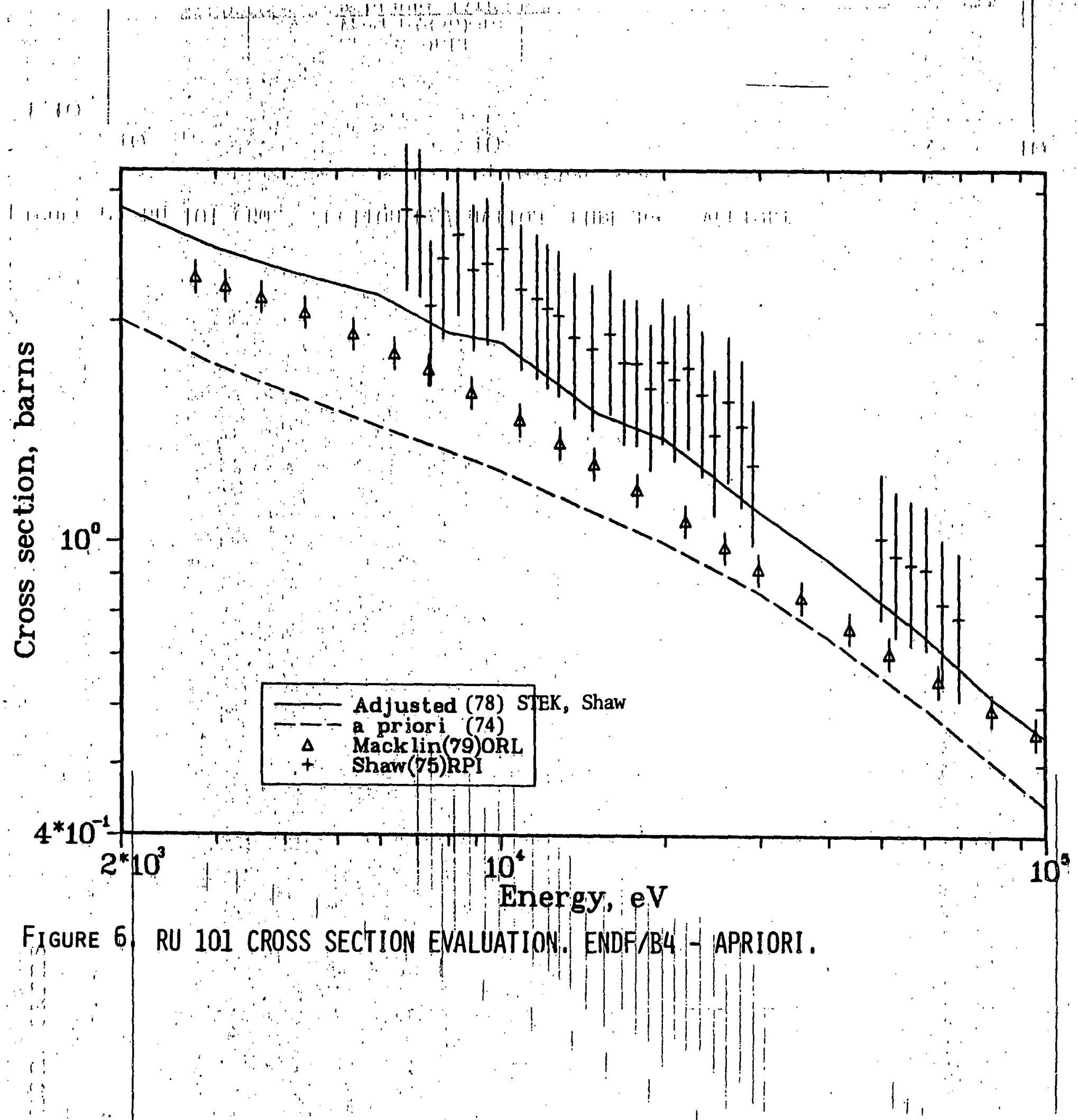



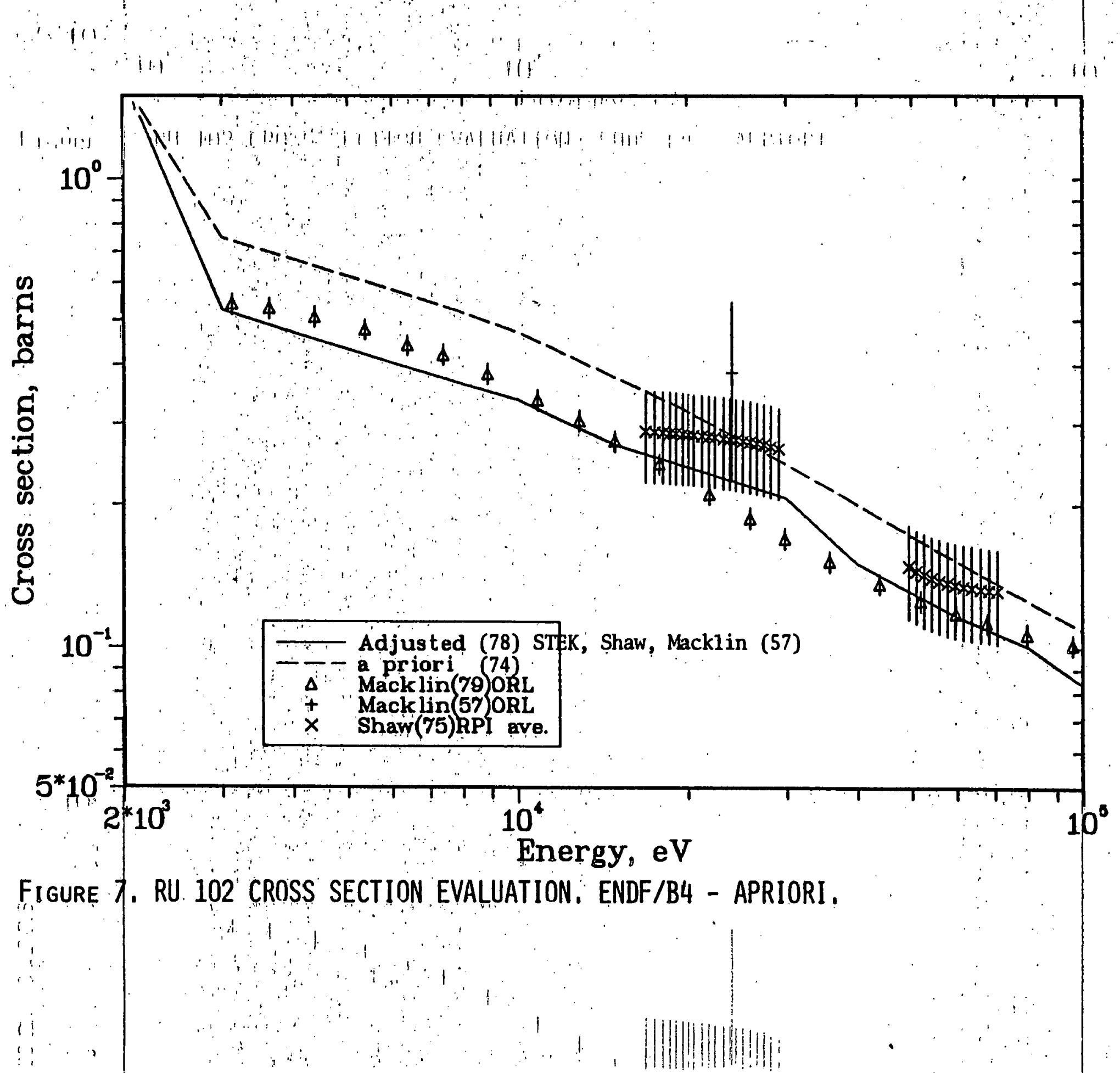


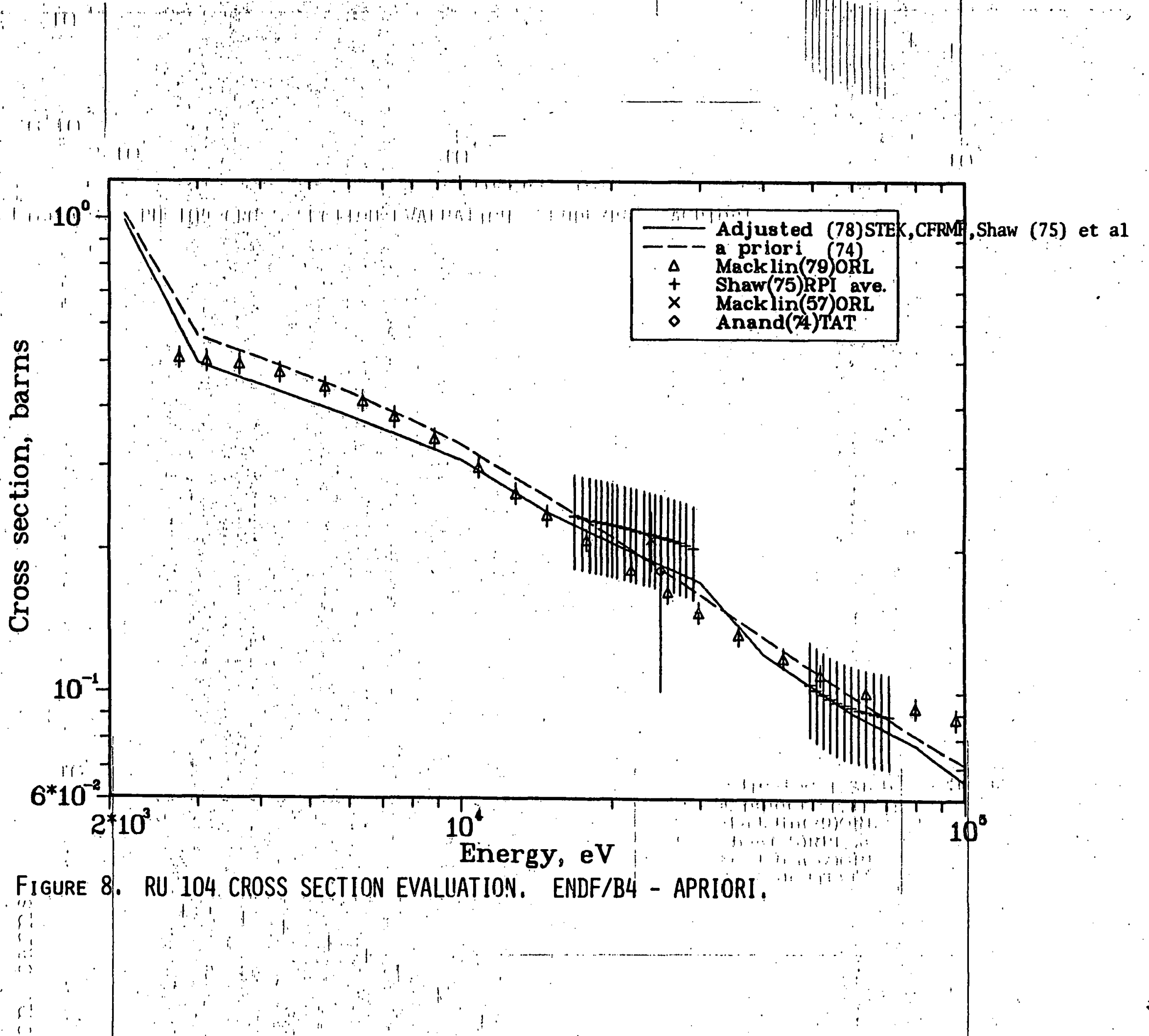




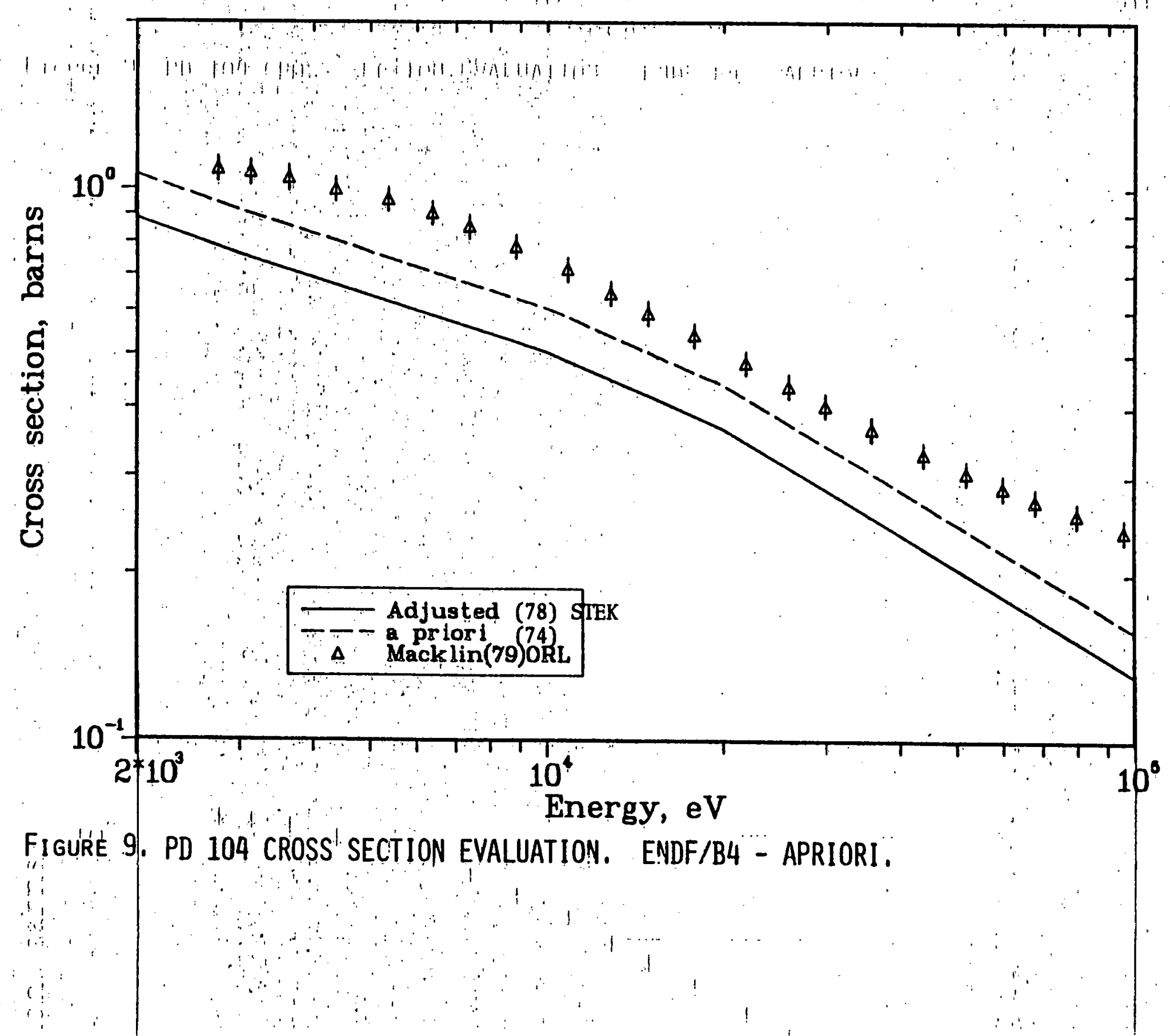




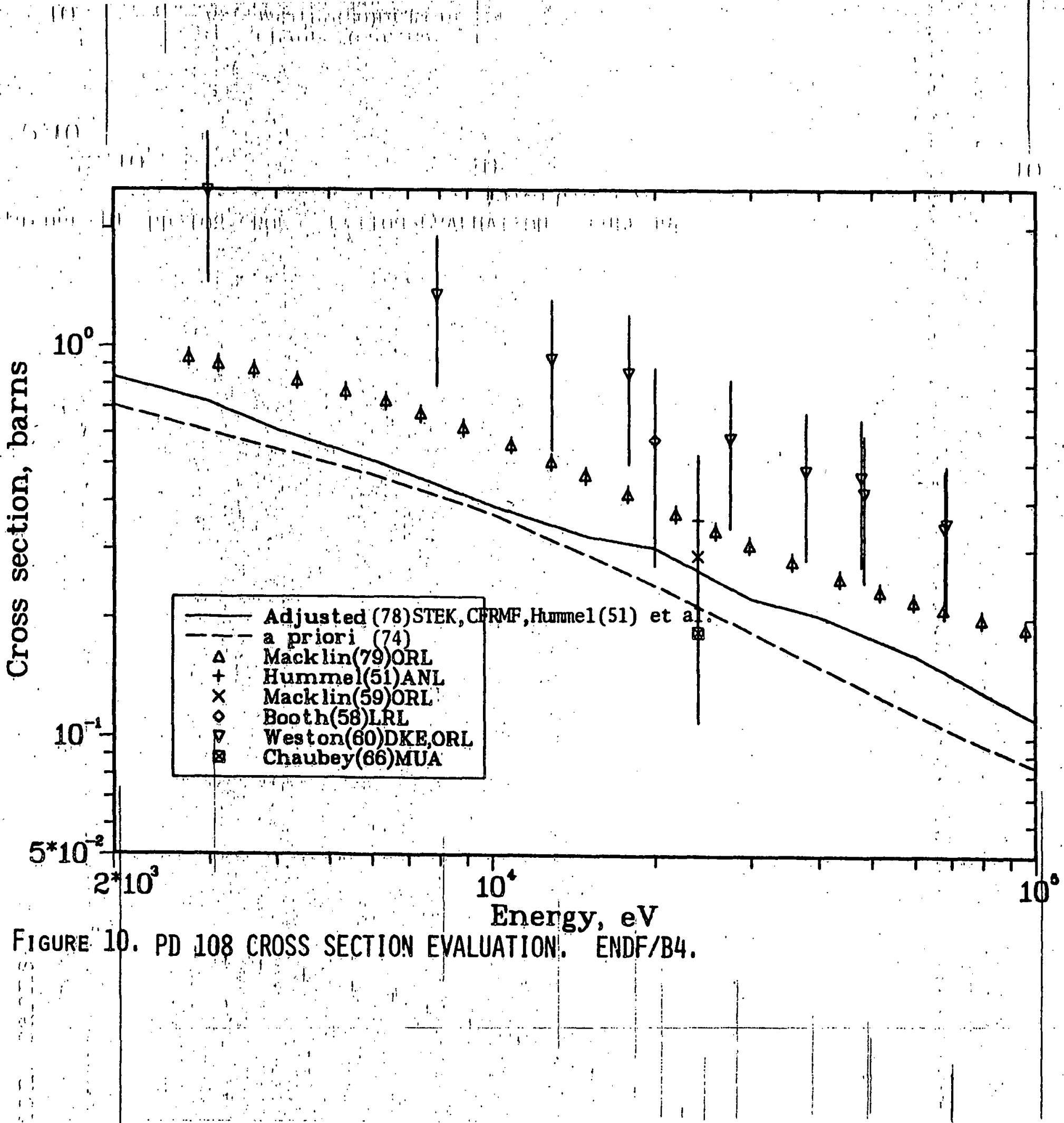




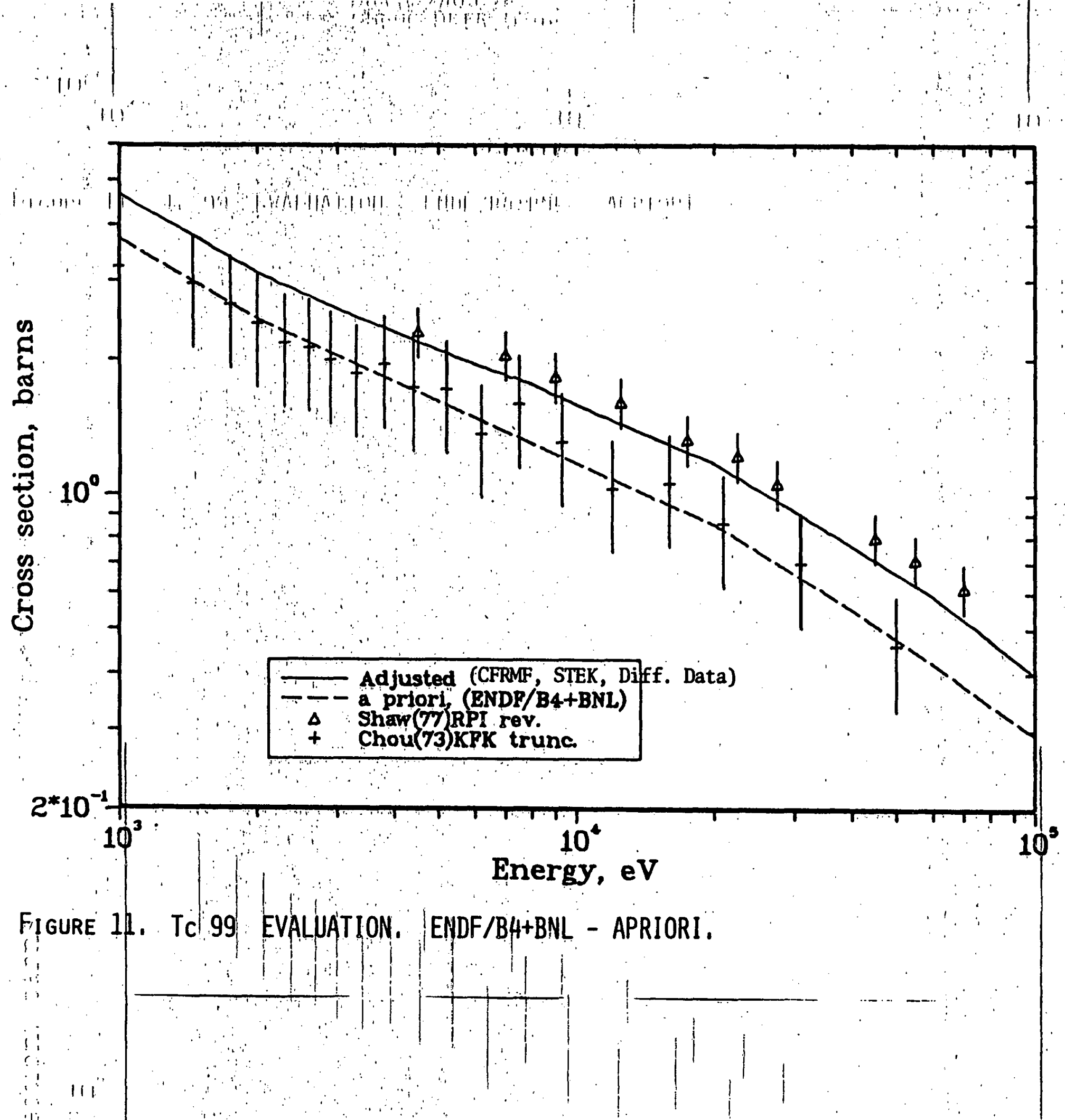




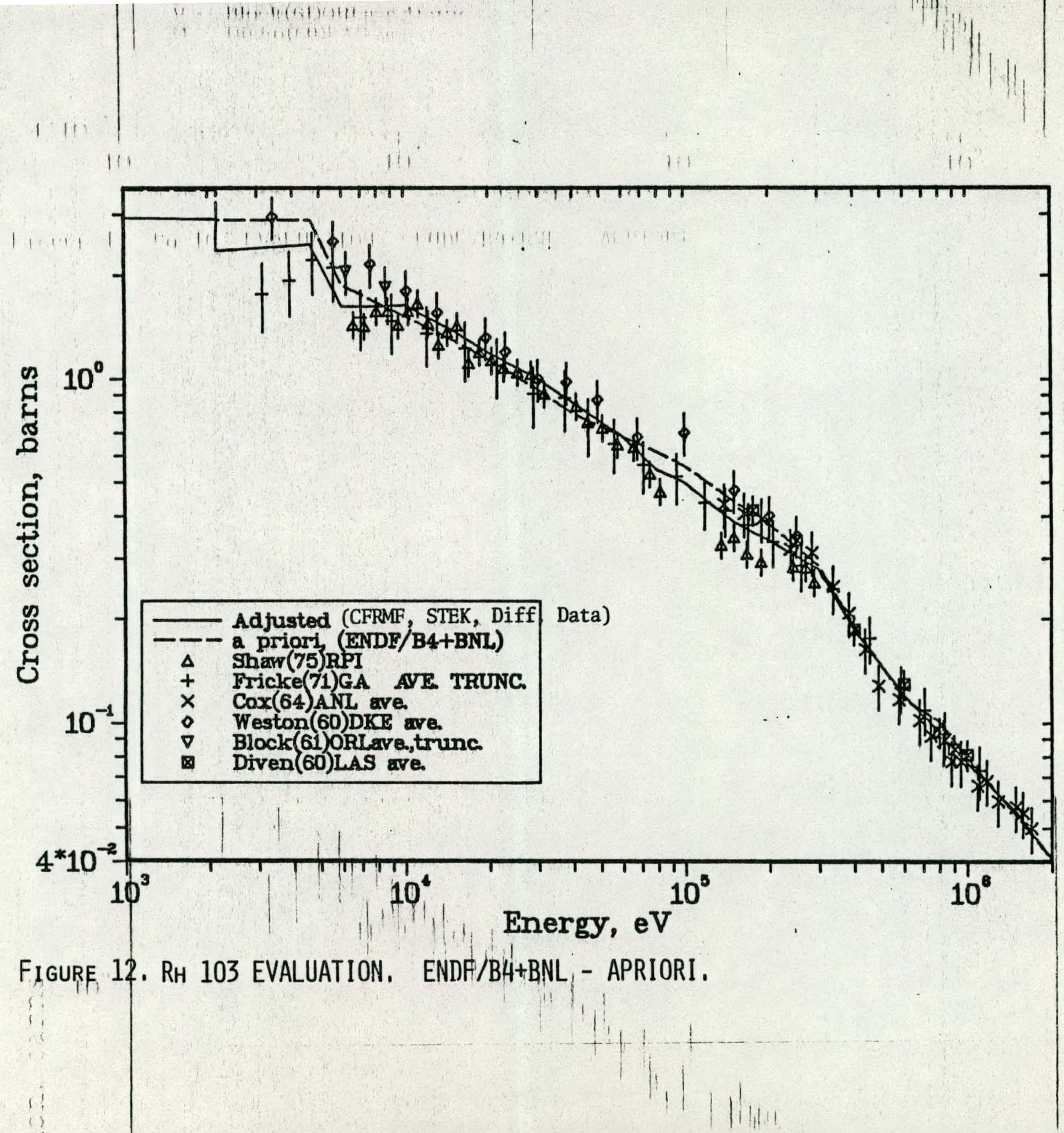




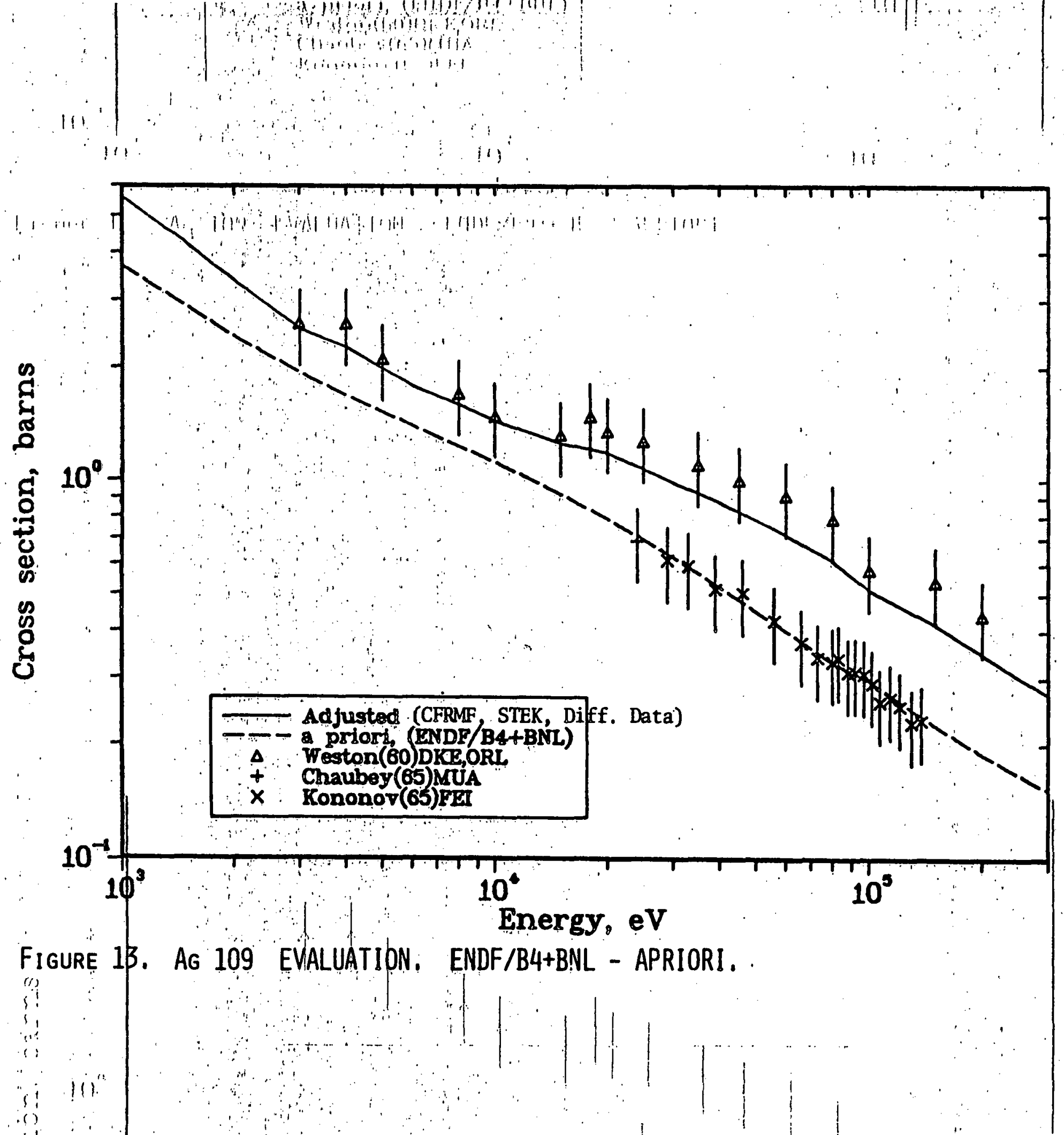




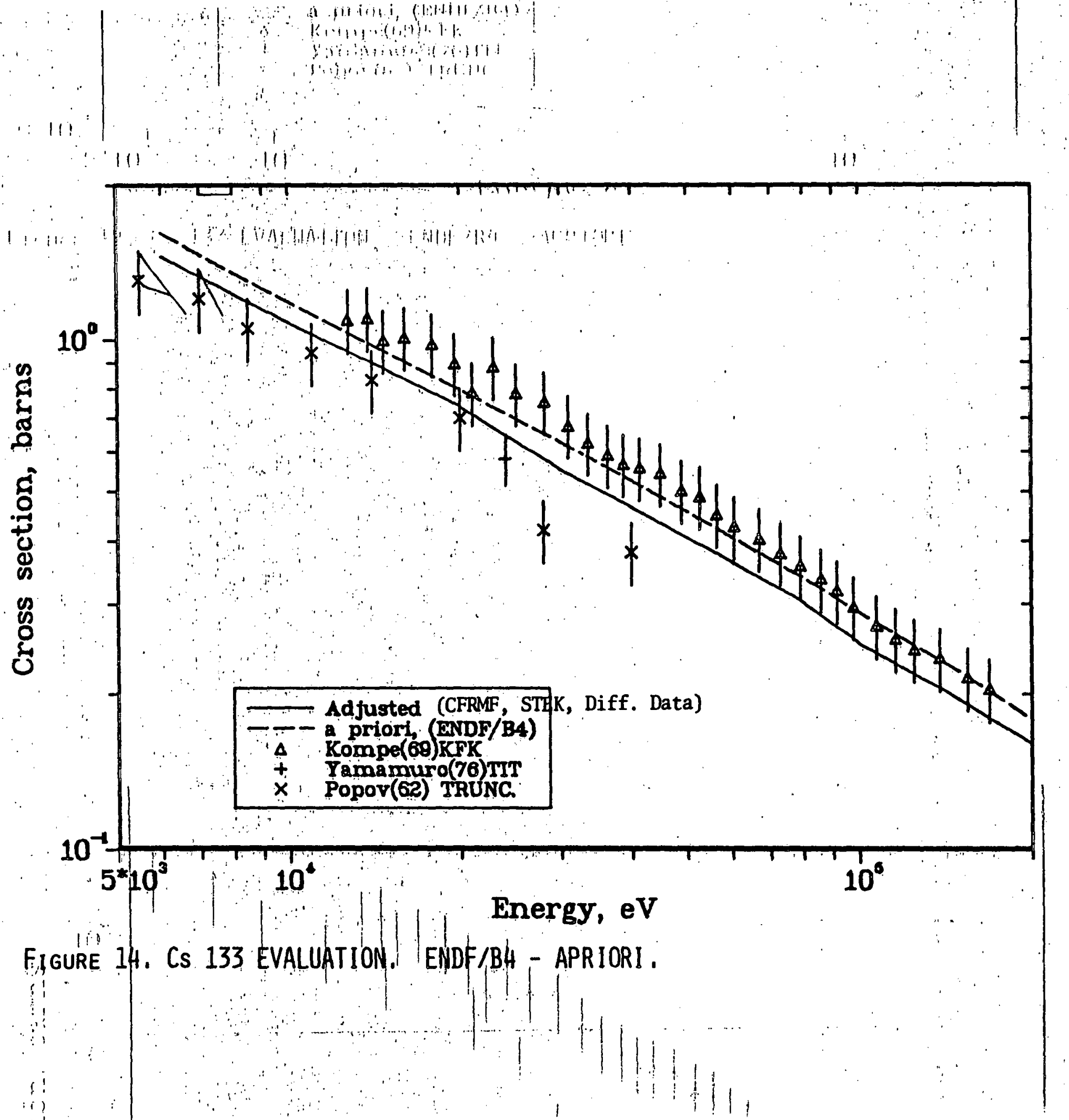




\section{THERMAL AND RESONANCE CAPTURE}

Table III gives the results of calculations of ENDF/B-4 resonance integrals (Ecut $=0.5, T=0^{\circ} \mathrm{K}$ ) and thermal cross sections for the major fission product absorbers in thermal reactors. These will form the basis of the - ENDF/B-5 evaluations. Also shown in Table III are the values given in $-B N L$ $325 / 3 /$ which for most cases are identical or very close to, the ENDF/B-4results. Most of the ENDF/B-5 "196 nuclides" with cross-section data will have "Fi.le 2" resonance parameter descriptions. The "File 3" smooth back-ground cross section will then be adjusted consistent with experimental results to give measured resonance integrals (within $1 \sigma$ ) and measured -thermalcross sections. The main source of experimental resonance integrals and -thermal values was BNL-325 which has almost identical agreement with the "Chart of the Nuclides". For those cases which BNL-325 did not list measured - values, other sources of data were from Clayton /9/, Ribon and Krebs /10/, Pope and Story $/ 11 /$, and Kirouac $/ 12 /$.

Appendix A provides thermal reactor absorption sensitivity analysis. 
Table III. Resonance Integrals and Thermal Cross Sections of Major FP. Absorbers in Thermal Reactors.

Resonance Integra 7.s. (barns)

Nuclide ENDF/B-4* BNL-325

Xe135 $7645 . \quad 7634$.

Sml49 3200. 3183.

Pml47 2283. 2300. \pm 350 .

Xe131 879.

Cs133 $381 . \quad 415 . \pm 15$.

Nd143 205.

Sm151 3357. 3300. \pm 700 .

Rh103 1050. 1100. \pm 50 .

Tc99 $354 . \quad 340 . \pm 35$.

Nd145 $226.240 . \pm 35$.

Sml52 3008. 3000. \pm 200 .

Pml 48M 3608. 3600 .

Mo95 $113.105 . \pm 7$.

Eu153 $1590 . \quad 1635 . \pm 200$.

Kr83 192.230.

Rh105 15850. 15800. \pm 1500

Sm150 320. 310. $\quad 15$.

Pmi48 40010. 40000.

Cs135 61.6. 62.

Rut01. 95.2 . 85.

Eul55 . 1856.

La139

Pri41.

Eu154

Pr143

Xe133

Cd113

Nd146

Cs 134

Mo97
13.0

1.9 .4

2700.

190.

356.

405.

3.3

213.

16.1
$12.2 \pm 0.6$

$14.1 \pm 0.2$

$3.2 \pm 0.5$
Thermal Capture Cross Sections (barns)

ENDF/B-4 BNL-325

$2.64 \times 10^{6} \quad(2.65 \pm 0.20) \times 10^{6}$

41190. $41000 . \pm 2000$.

$182 .-181 . \pm 7$.

90. $90 . \pm 10$.

$29.5 \quad 37.5 \pm 1.5$

$325 . \quad 325 . \pm 10$.

15000 . 15000. \pm 1200 .

148。 $150 . \pm 5$ 。

$19.19 . \pm 2$.

42. $42 . \pm 2$.

206. 206. \pm 6 .

10600. 22000. \pm 2500 .

$14.5 \quad 14.5 \pm 0.5$

453. $390 . \pm 30$.

208. 200. \pm 30 .

16000 . $16000 . \pm 1500$.

$102 . \quad 102 . \pm 5$.

2000. 2000 \pm 1000

$8.7 \quad 8.7 \pm 0.5$

$3.1 \quad 3.1 \pm 0.9$

4040. . 4040. 125 .

9.0

9. $0+0.3$

$11.5 \quad 17.5 \pm 0.3$

1500 . : $1500 . \pm 400$.

89 . $\quad 89.10$.

$190 . \quad: 190 . \pm 90$.

$19880 . \quad 19910 . \pm 300$.

1.4

$1.4 \pm 0.1$

140 . T40. \pm 12 .
2.2
$2.2 \pm 0.7$

$\overline{{ }^{*} \mathrm{ECUT}}=0.5 \mathrm{eV}, T=0^{\circ} \mathrm{k}$ 


\section{REFERENCES}

1.:. F: Schmittroth, "Generalized Least-Squares for Data Analys is";. HEDL-TME 77-51. (March 1978).

2:. F. Schmittroth, "FERRET Data Analys is Code", HEDL-TME 79-40;- (Sept:1979).

3. S.F. Mughabghab and D.I. Garber, "Neutron Cross Sections, Vol. I , Resonance Parameters", BNL 325, June 1973.

4.- J.W.M. Dekker, ECN-14,. February 1977.

5. Y.D. Harker, et a1., EGG Report 1977, Kiamesha Lake Ta1k, 1972.

6. F. Schmittroth, "Theoretical Calculations of Fast Neutron Capture Cross Sections", HEDL-TME 71-106, (August 1971).

7. R.A. Anderl, et al., "Neodymium, Samarium and Europium Capture-Cross Section Adjustments Based on EBR-II Integral Measurements , International Conference on Nuclear Cross Sections for Technology, Knoxville, Tennessee, October 22-26, 1979.

8. R.L. Macklin, et al. "100, 101, 102, ${ }^{104} \mathrm{Ru}(n, \gamma)$ and ${ }^{103} \mathrm{Rh}(n, \gamma) \cdot$ Cross Sections above $2.6 \mathrm{KeV"}$ and "104, 105, 106, 108, 110 $\mathrm{Pd}(\mathrm{n}, \gamma)$ Cross-Sections" to be published and Nucl. Sci. Eng. 71, p. 182-191 (1979).

9. E. Clayton, AAEC/TM 619 (Sept. 1972).

10. P. Ribon and J. Krebs, Bologna Panel Report (Apri.1 1974).

11. A. L. Pope and J.S. Story, AEEW-M 1234 (1973).

12. G.J. Kirouac, et al., Nuc. Sci. and Eng., 52, 31.0 (1973.). 


\section{FISSION-PRODUCT ABSORPTION IN THERMAL REACTORS: MAJOR CONTRIBUTORS} AND CROSS-SECTION SENSITIVITIES

All sensitivity data in this appendix are based on ENDF/B-IV; the ENDF/B-V files were not complete in time for a processing and sensitivity study before this meeting. However for thermal reactors, the cross-section changes are not 11kely to be signiflcant to aggregate absorption buildup, and the sensitivities in this appendix can be used to predict the results of specific cross-section changes between Version IV and V.

The cross sections used in this study are listed in Refs. 1 and 2. These were first processed using NJOY/3/ in 154 energy groups and then spectrum welghted into the 4-group structure defined in Table A-I using a typlcal mid-life spectrum for LWR's. The function is illustrated in Fig. A-1 and Ilsted in Ref. 1. A detalled listing of the 4-group cross sections will be available for this meeting, and differences in $\sigma_{2200}$ and RI between Versions IV and $V$ noted.

The depletion and buildup calculations also require decay and yield data. Decay parameters are listed in Ref. 4; ENDF/B-IV ylelds are essentialIy those listed in Ref. 5, except for minor changes in independent yields that are of no significance to this study. The basic depletion calculations use a $3.3 \mathrm{w} / \%$ U-235 enriched fuel at a constant power level of $30 \mathrm{Mw} / \mathrm{MT}$ for a total burnup of $33 \mathrm{GWd} / \mathrm{MT}$. Power and fission-product production was from the constantly changing production of $\mathrm{Pu}-239$ and concomitant depletion of $\mathrm{U}-235$ and U-238. The content and 4-group macroscopic absorption of each fission product was calculated at 33 times in increments of $800 \mathrm{~h}$ ( 1 GWd/MT) out to $26400 \mathrm{~h}$ (approximately $3 \mathrm{yr}$ ). A large number of such calculations were required for the sensitivity studies.

A11 parameters affecting the major nuclides contributing to the aggregate absorption were examined./6/ Space 1 imits this appendix to a condensed summary of the results at two times in reactor life and to crosssection data. However, those readers interested in fission-product absorption in thermal reactors should remember that, depending on the nuclide, cross sectlons are not always the most important parameter. For example, at approximately $20 \mathrm{GWd} / \mathrm{MT}$ depletion, the yields, branching fractions, and decay constants account for 26 of the largest 40 sensitivities. Furthermore, those nuclides having very large cross sections such as Sm-149 have relatively small cross-section sensitivities in LWR's. The reason for this behavior is simply that the products are both produced and depleted, and therefore those stable nuclides having large cross sections tend to reach an equilibrium macroscopic value determined only by the production (yield) rate; at constant power, the cross section determines the time of equilibrium, not the ultimate absorption rate. It is also true that an increase in the cross sections of some nuclides (e.g., Nd-147) can decrease the aggregate absorptton, an effect due to the reduction of the decay branching to daughters having large cross sections. These statements are not intended to reduce the importance of cross sections. In fast reactors and in transient phenomena in IWR's, the cross sections are of domfnate importance.

IMPORTANT NUCLIDE ABSORBERS IN 'LWR's

Table A-II lists 64 nuclides that contribute $>0.1 \%$ to the aggregate thermal, epithermal, or total absorption at some time during the $33 \mathrm{Gwd} / \mathrm{MT}$ depletion. The specific contribution at 33 times of 10 of the most important contributors. Is listed in Table A-III. 


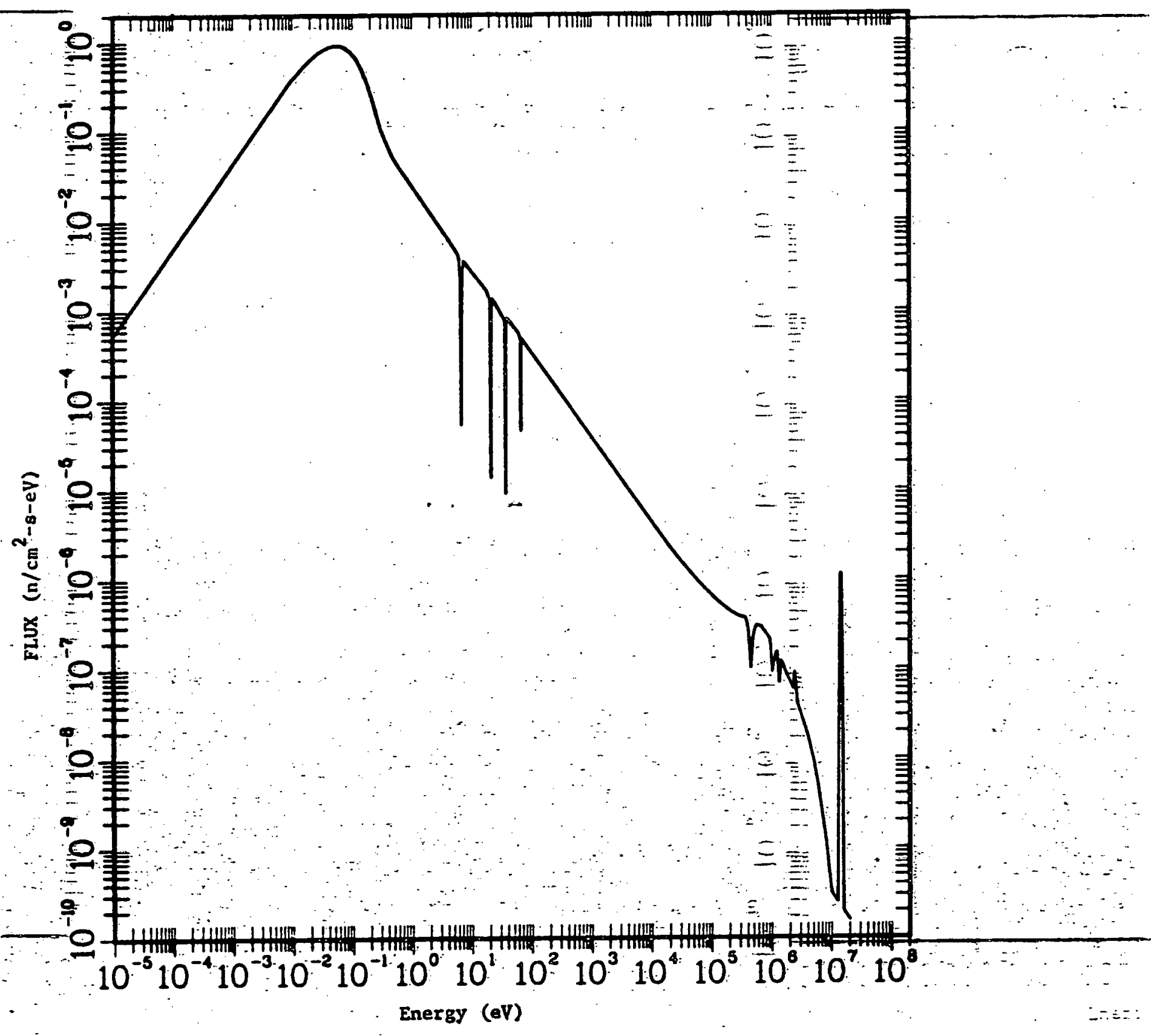

Fig. A-1

Flux weighting function. 
The chain systematics of each of the 64 nuclides was examined to determine the most important parameters (291) affecting their total absorption, and sensitivites were calculated./6/

\section{SENSITIVITIES}

Thermal and epithermal cross sections were individually increased by $10 \%$, one at a time, and the change in aggregate absorption calculated.: The tabulated sensitivity, $S$, of the aggregate absorption rate, $R_{T}$, was cal- culated from the change, $\Delta R_{T}$, where $R_{T}$ is a sum over all groups and nuclides.

$$
S \equiv \frac{\Delta R_{T} / R_{T}}{\Delta \mathrm{X} / \mathrm{X}},
$$

where $\Delta x$ is the $10 \%$ increase in efther a thermal or epithermal (resonance) cross section $X$. Values of $S$ thus represent the direct change in the aggregate absorption per unit change in one of these cross sections. Values of $s<10^{-5}$ are 11sted as io.

Table A-IV 1ists the resulting sensitivities at two depletion times, $5 \mathrm{GWd} / \mathrm{MT}$ and $33 \mathrm{GWd} / \mathrm{MT}$ (4000 and $26400 \mathrm{~h}$ ). A total of 78 nuclides were examined; that is, the list includes sensitivities for cross sections coupled to the initial 64 in Table A-II. An ordered 11st of the largest 15 sensitivities at both depletion times is given in Table A-V.

Sensitfvities do not show the actual importance of the major contributors. Tables A-VI and A-VII show the percent contribution to the total, thermal, and resonance absorption, ordered on the total absorption for the major contributors.

\section{REFERENCES}

1. W. B. Wilson and T. R. England, "Multigroup and Few-Group Cross SectIons for ENDF/B-IV Fission Products: The TOAFEW Collapsing Code and Data File of 154-Group Fission-Product Cross Sections," LA-7174-MS (1978).

2. T. R. England, W. B. Wilson, and M. G. Stamatelatos, "Fission-Product Data for Thermal Reactors, Part 1, A Data Set for EPRI-CINDER Using ENDF/BIV," LA-6745-MS (1976) and "Fission Product Data for Thermal Reactors, Part 2, Users Manual for EPRI-CINDER Code and Data;" LA=6746-MS (1976). [Also published by Electric Power Research Institute as EPRI-NP-356-(Dec. 1976)].

3. R. E. MacFarlane et a1., "The NJOY Nuclear. Data. Processing. System:- User's Manual," LA-7584-MS (Dec. 1978).

4. Fission-Product Decay Library of the Evaluated Nuclear Data Files,- Version- IV (ENDF/B-IV, available from and malntained by the National Nuclear Data Center at the Brookhaven National Laboratory. For a list of decay parameters, see T. R. England and R. E. Schenter, "ENDF/B-IV Fission-Product Files: Summary of Major Nuclide Data," LA-6116-MS [ENDF-223] (Oct. 1975).

5. M. E. Meek and B. F. Rider, "Compilation of Fission Product Yields," NEDO-12154-L (Jan. 1974). 
6. W. B. Wilson and T. R. England, "Status of Fission-Product Data for Absorption Calculations," In Symposium Proceedings: Nuclear Data Problems for Thermal Reactor Applications, EPRI NP-1098 (June 1979).

TABLE A-I

4-GROUP ENERGY STRUCTURE AND FLUX RATIOS

$\begin{array}{llll}\text { Group } & \begin{array}{l}\text { Energy } \\ \text { Boundary } \\ \mathrm{eV}\end{array} & \begin{array}{l}\text { Lethargy } \\ \text { Width }\end{array} & \begin{array}{l}\text { LWR Flux } \\ \text { Ratios to } \\ \text { Thermal* }\end{array} \\ 1 & 8.2085 \times 10^{5} & 2.5 & 1.4759 \\ 2 & 5.5308 \times 10^{3} & 5.0 & 2.3401 \\ 3 & 9.2506 \times 10^{-1} & 8.088 & 1.7833 \\ 4 & 1.0 \times 10^{-5} & & 1.0 \\ & & & \\ \text { * } & & \\ \text { The degree of spectrum hardness used is indicated } \\ \text { by the average value, } 0.554018, \text { of a unit } 1 / \mathrm{v} \text { cross } \\ \text { section at } 0.0253 \mathrm{eV} \text {. }\end{array}$


RUCLIDES CONTRIBUTING GREATER IHAN 0.17 OF THERMAL, EPITHERMAL

OR TOTAL FISSION-PRODUCT ABSORPTION RATE AT SOME TIRE DURING EUEL HISTTORY

(to $33.000 \mathrm{kWd} / \mathrm{MT}$ )

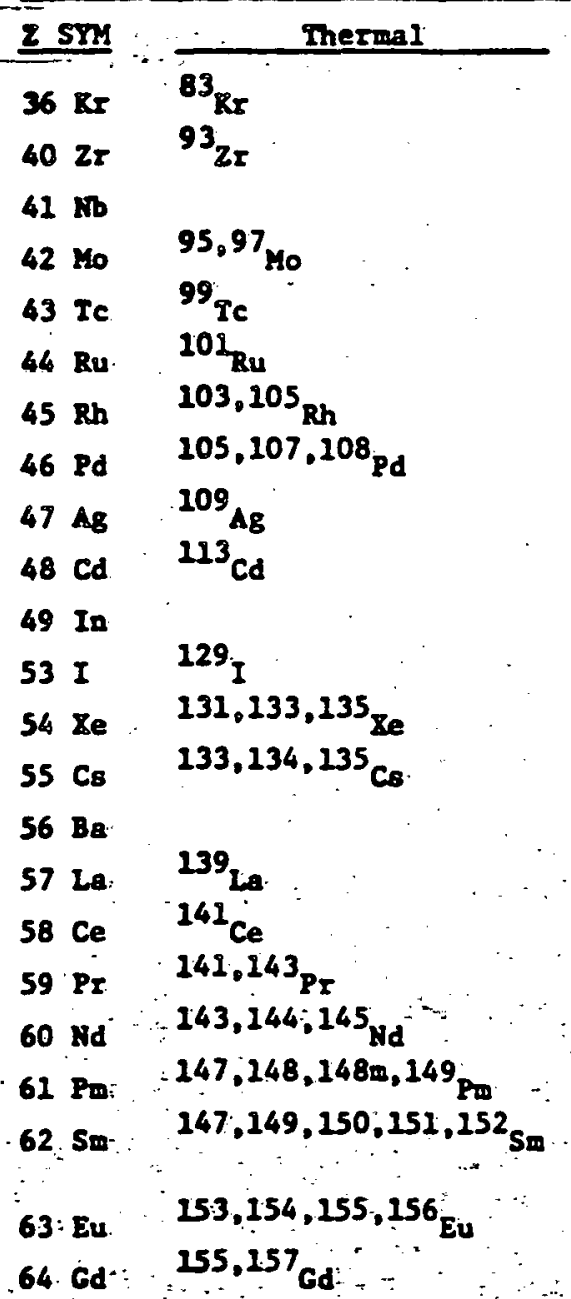

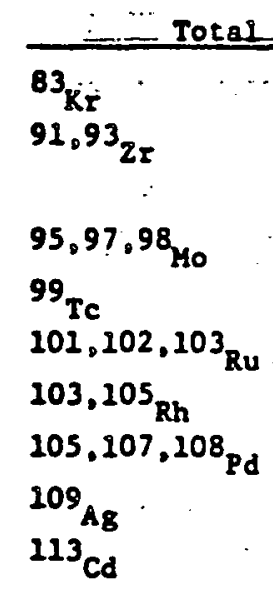

$129_{1}$

$131,133,135 \mathrm{Xe}$

$133,134,135 \mathrm{CE}$

$1399_{\text {La }}$

$141 \mathrm{Ce}$

$141,143 \mathrm{Pr}$

$143,144,145,147,148$ Nd

$147,148,148 \mathrm{~m}, 149 \%$

147,$149 ; 150,151,152 \mathrm{sm}$

$153,154,155,156 \mathrm{Eu}$

157 Gd 
TABLE A-III

COATRIBUT TONS OR TEN MUNOR NUCLIDES TO THE TOTAL NEUTRON ABSORPTION RATE OP PISSION PRODUCTS

Percent of Total F1seion-Product Absorption Race

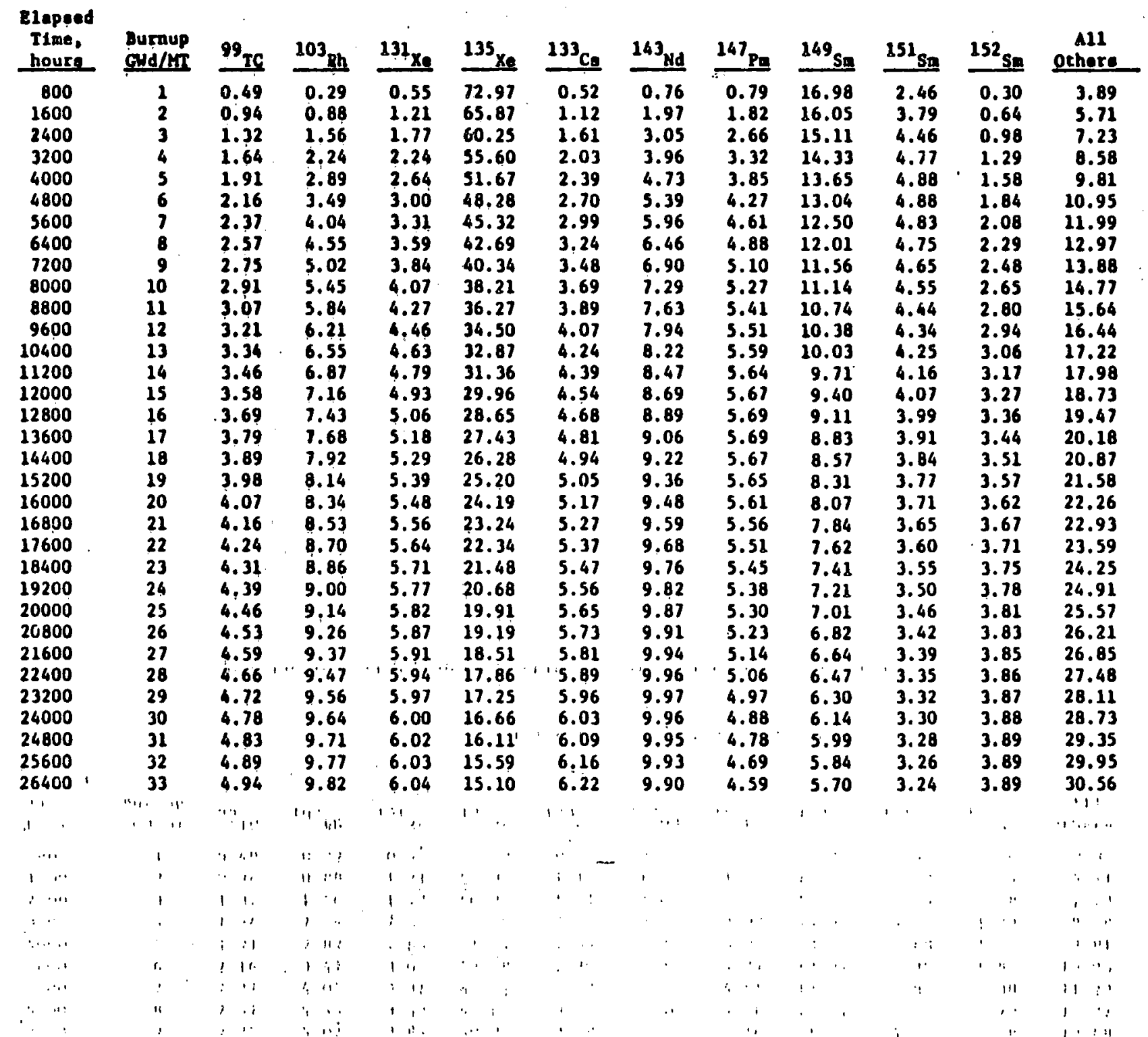


TABLE A-V

ORDARTD LIST OF THE PIRST 16 MOST IMPORTANT CROSS SJCTION SINSITIVITIES AT 5 AND 33 GId/MT

\begin{tabular}{|c|c|c|}
\hline Nuolide & $x-s e c$ type & Senoltivity \\
\hline 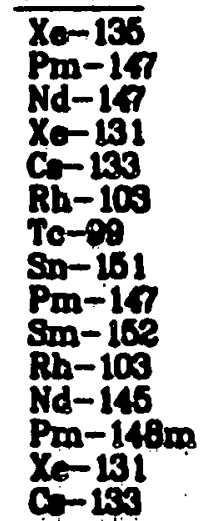 & $\begin{array}{l}\text { Thermal } \\
\text { Epithermal } \\
\text { Thermal } \\
\text { Eplthormal } \\
\text { Eplthermal } \\
\text { Epithermal } \\
\text { Epithermal } \\
\text { Thermal } \\
\text { Thermal } \\
\text { Eplthermal } \\
\text { Thermal } \\
\text { Pplthermal } \\
\text { Thermal } \\
\text { Thermal } \\
\text { Thermal }\end{array}$ & $\begin{array}{l}.13693 \\
.04775 \\
.04025 \\
.01808 \\
.01851 \\
.01709 \\
.01562 \\
.01460 \\
01391 \\
.01242 \\
.01029 \\
.00737 \\
.00097 \\
.00012 \\
.00512\end{array}$ \\
\hline
\end{tabular}

\begin{tabular}{|c|c|c|}
\hline cide & $x-\sec$ type & Sennitivity \\
\hline 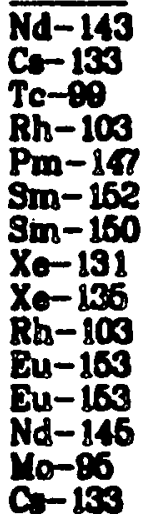 & $\begin{array}{l}\text { Thermal } \\
\text { Epithermal } \\
\text { Ppithermal } \\
\text { Bpithermal } \\
\text { Bpithermal } \\
\text { Bpithermal } \\
\text { Thermal } \\
\text { Eplthermal } \\
\text { Thermal } \\
\text { Thermal } \\
\text { Epithermal } \\
\text { Thermal } \\
\text { Epithermal } \\
\text { Bpithermal }\end{array}$ & 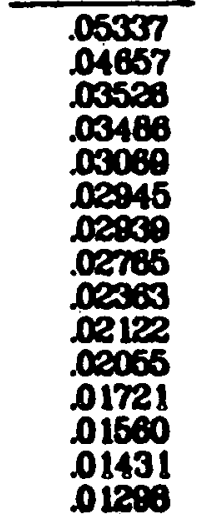 \\
\hline
\end{tabular}

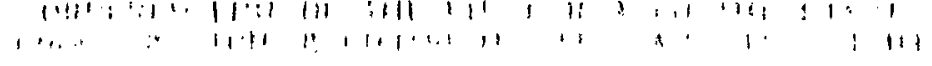

\begin{tabular}{|c|c|c|}
\hline nithinin & $k$ ins: |y. & .13i11::11 \\
\hline$x_{n} \quad i x$ & $1 l_{161}+1, \ldots 1$ & $\begin{array}{l}110 i+1 \\
111,14\end{array}$ \\
\hline$\| i n \mid 1 i$ & Pll, $\left.{ }_{1}, n_{n}\right)$ & i) $110 \div \div$ \\
\hline
\end{tabular}

\begin{tabular}{|c|}
\hline !1:4 11:1 \\
\hline i. ii \\
\hline
\end{tabular}

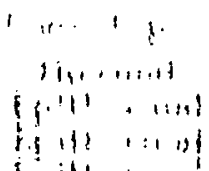

anifinil,

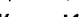

חin:

1.6
$\cdots 1$

1110110

Ii) IIi

(D) 
TABLE A-VI

SUMMARY OF MAJOR FISSION-PRODUCT TOTAL ABSORBERS AT 4000 HOURS

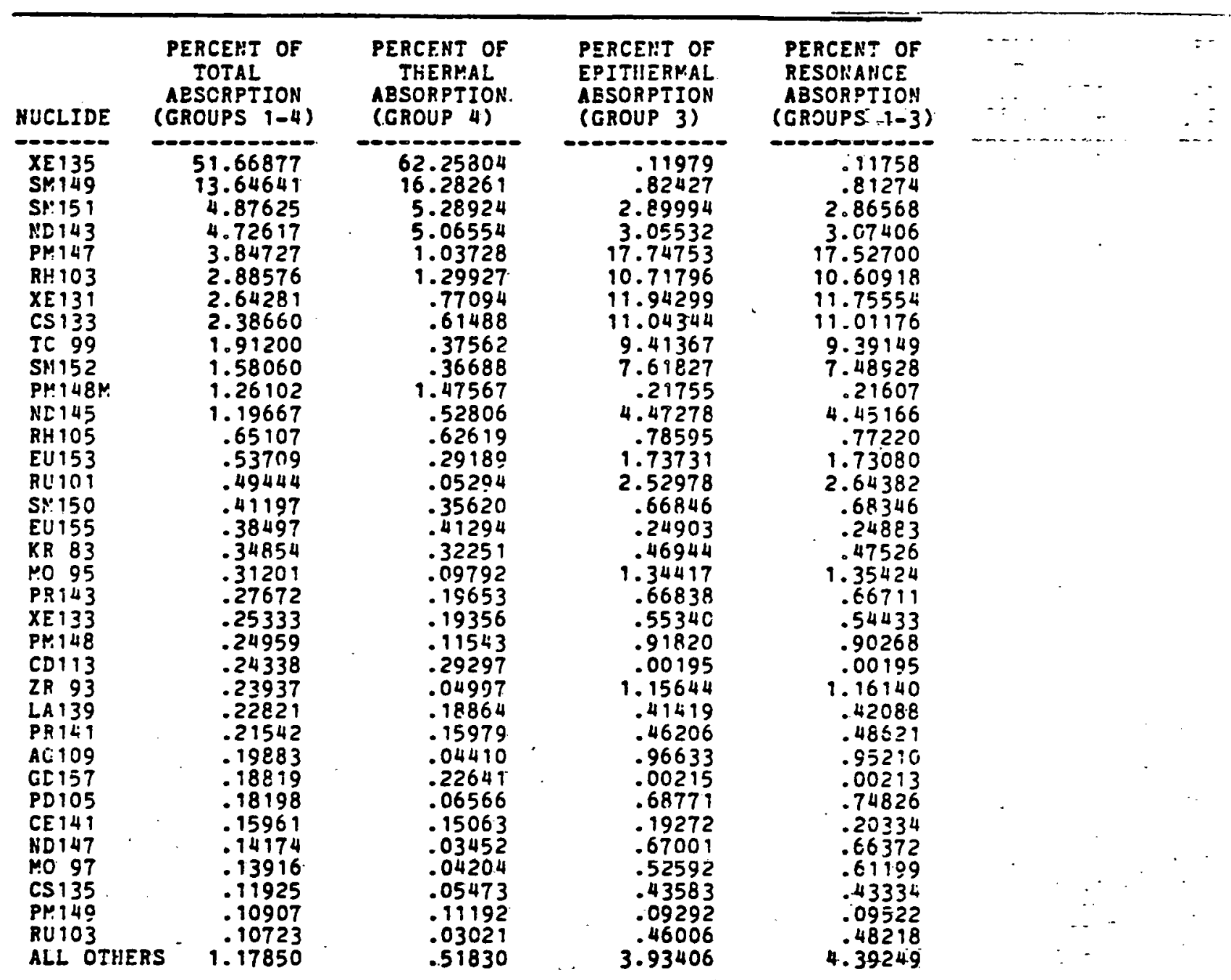


TABLE A-VII

SUMYARY OF MAJOR FISSIOH-PRODUCT TOTAL ABSOREERS AT 26400 HOURS

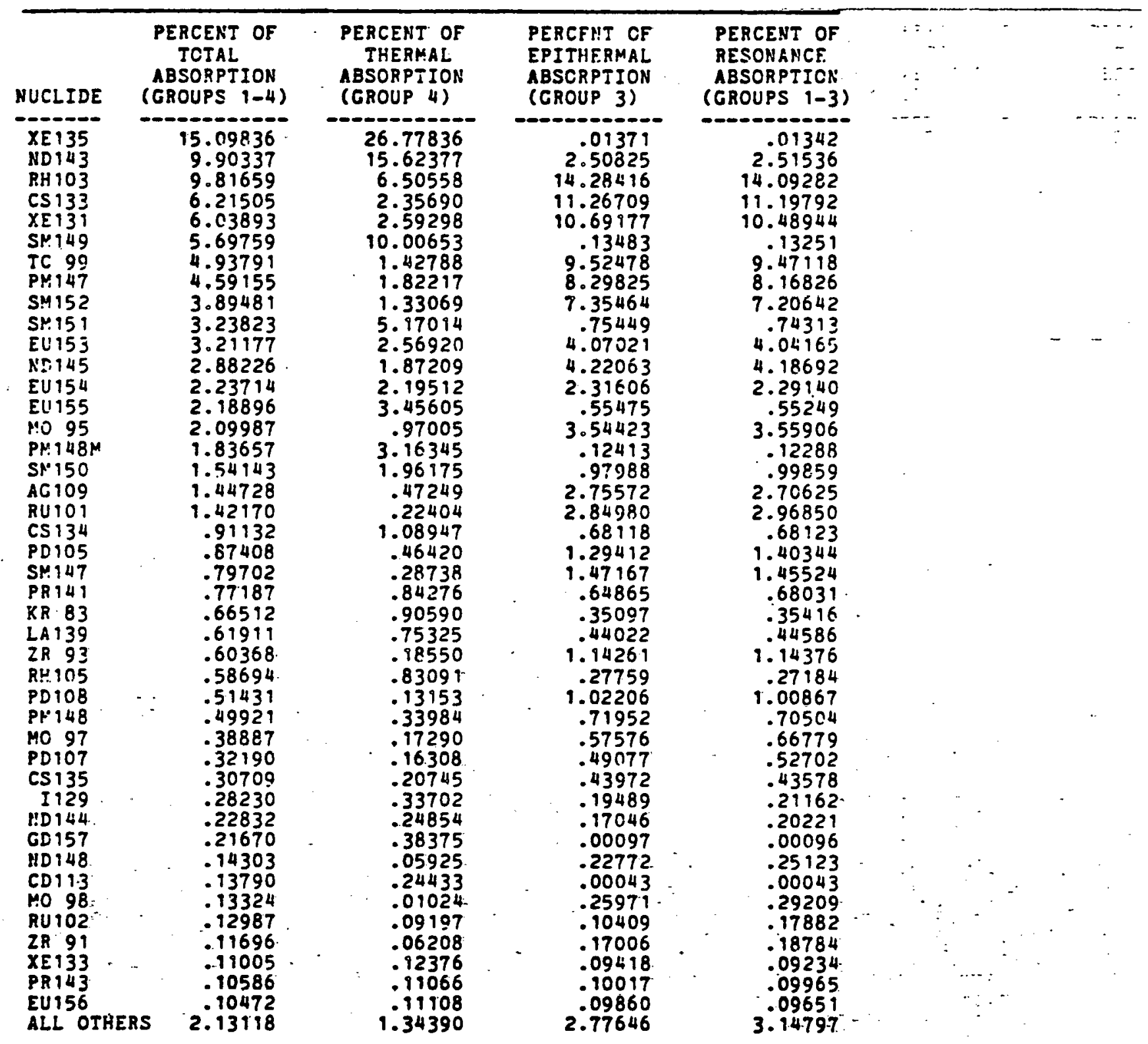

